\title{
Attachment Preferences of L2 Learners in a Production Task
}

\author{
Hadi Maghsoud ${ }^{1, *}$ \\ ${ }^{1}$ Faculty of Foreign Languages and Literatures, University of Tehran, Tehran, Iran \\ *Correspondence: Faculty of Foreign Languages and Literatures, University of Tehran, Tehran, Iran. E-mail: \\ hadi.maghsoud@gmail.com
}

Received: April 8, 2018

doi:10.5430/ijelt.v5n2p50
Accepted: May 13, 2018 Online Published: July 15, 2018

URL: https://doi.org/10.5430/ijelt.v5n2p50

\begin{abstract}
This study investigated whether L2 learners of English process sentences semantically or syntactically when they are engaged in production rather than comprehension. Thirty-four Persian speaking second language learners of English across two proficiency levels participated in a production task which involved completing sentences such as Andy shot the man with... with a determiner phrase (DP) of their own choice. In majority of cases, the participants across both proficiency levels supplied DPs that were semantically related to the verb (i.e., semantic-based processing). The findings are argued to support the constraint-based theories and shallow structure hypothesis.
\end{abstract}

Keywords: production, syntax, semantics, attachment preference, determiner phrase, prepositional phrase

\section{Introduction}

Psycholinguists involved in research on ambiguity resolution have many concerns such as identifying the initial source that determines a specific reading of temporarily ambiguous sentences, whether this initial reading proves to be right or wrong at a later analysis, whether sources of information are taken care of step by step or simultaneously, whether there is an interaction between sources of information, and whether the processing strategies are universal (Papadopoulou, 2006).

Research in the field of processing initially considered the phrase structure as the main driving force behind attachment preferences. The dominance of syntax was later questioned by bolding the role of semantics and pragmatics (Altmann \& Steedman, 1988). Since then, finding out sources of information, other than syntax, that guide attachment preferences has been the subject of many studies. The sources of information individuals make use of to come up with the correct interpretation of an ambiguous sentence could be extra- and intrasentential. While extrasentential sources information such as context (Ferreira \& Clifton, 1986; Britt, Perfetti, Garrod, \& Rayner, 1992; Altmann \& Steedman, 1988; Tanenhaus et al., 1995) and priming (e.g., Branigan, Pickering, \& McLean, 2005) refer to clues outside a sentence, interasentential information such as animacy (Trueswell, Tanenhaus, \& Garnsey, 1994), definiteness (Spivey-Knowlton \& Sedivy, 1994) and argument structure of the verb (Frenck-Mestre \& Pynte, 1997) is embedded within a sentence.

In general, contributors to research in the area of ambiguity resolution divide into two camps holding two different views about processing. The first camp pioneered by Lyn Frazier advocate priority of syntax in initial analysis of ambiguous sentences. The other camp maintain that other sources of information are determining in the first analysis. The two conflicting views of processing are represented by the garden path theory (Frazier \& Rayner, 1982) and the constraint based theories. The garden path theory advocates syntactic parsing and that parsing is an autonomous phenomenon which occurs without initial engagement of semantics. For example, sentence (1) has two interpretations which are presented as tree diagrams below.

(1) The man saw the girl with leather gloves. 

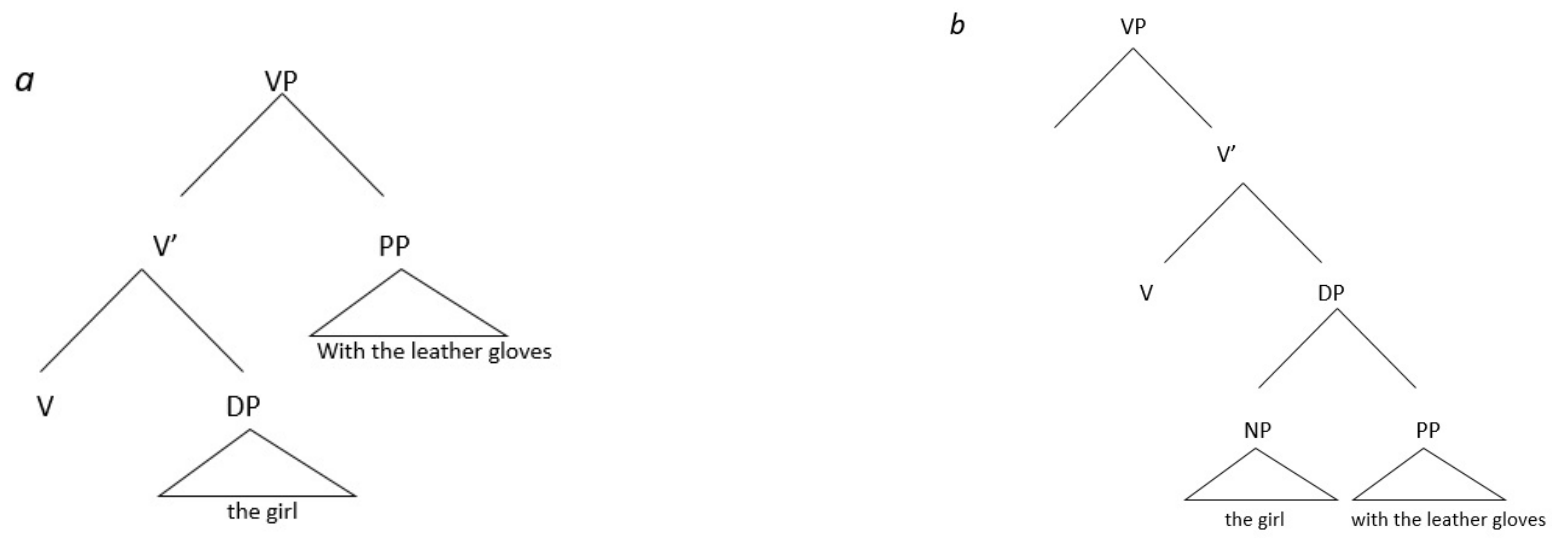

Readers might initially attach the prepositional phrase (PP) with the leather gloves either to the verb saw or to determiner phrase (DP) the girl. Based on minimal attachment strategy, which is one of the offshoots of the garden path theory, it is believed that learners first associate the PP with the verb (high attachment) as in tree diagram $a$ and only later are lexical or contextual information integrated if there is a need for reanalysis.

Moreover, in late closure, as the other strategy associated with the garden path theory, the new words attach to the phrase or clause that is being processed. As an example, late closure predicts processing a mile as the object of jogs and not the subject of the next clause in (2).

(2) Since Jay always jogs a mile seems like a short distance to him.

Unlike the garden path theory, the constraint-based theories assume that in initial attachment of the intended sentence elements in (1) and (2) all sources of information (i.e. background knowledge, semantics, context, etc. together with syntax) are integrated and a competition occurs between readings which is resolved in favor of the one with more support.

Strategies employed by L2 learners to resolve ambiguity has become the focus of recent research. Felser, Roberts, Marinis, and Gross (2003) investigated the relative clause attachment ambiguity preference of adult German and Greek learners of English. They found that L2 learners rely on semantics rather than syntax in their initial analysis. Dussias (2003) studied how bilinguality might influence relative clause (RC) attachment preference. The two bilingual groups (L1 English-L2 Spanish; L1 Spanish-L2 English) showed the same low attachment preference in their native and second languages. However, generally, Spanish and English monolinguals preferred high and low $\mathrm{RC}$ attachment respectively. He argued that native speakers and L2 learners process ambiguity differently because

[A]t points in which the grammar does not dictate a specific analysis of a sentence ..., the cognitive pressure and memory-load demands associated with housing two linguistic systems constrain the bilingual parser to use operations such as late closure [i.e., attachment to the most recent entity] (ibid., p. 552)

$\mathrm{He}$, also, mentioned the effect of language exposure as another probable reason for the results.

In their study of relative-clause attachment preferences, Papadopoulou and Clahsen (2003) reported parsing differences between Greek native speakers and proficient Greek learners with different L1s. The findings revealed that lexical features determined L2 learners' preferences. This was in contrast to native speakers' attachment preference which was based on phrase structure rules. Moreover, No L1 transfer was observed in L2 learners.

Clahsen and Felser (2006) introduced shallow structure hypothesis (SSH) which maintains that processing might be conducted at two levels. Syntax plays a major role in the initial processing level. This level is specified to native speakers. The second level is characterized by integration of syntax, semantics and other sources of information. According to SSH, native speakers and 12 leaners are first and second level (shallow) parsers respectively. However, later research showed that assumptions of SSH are questionable. McDonald (2006) argued that accessibility of syntactic information is influenced by processing difficulties such as working memory capacity and decoding ability regardless of being a native or a second language speaker.

Moreover, Witzel, Witzel, and Nicol (2012) examined the online comprehension of three types of temporary ambiguity, namely RC attachment, adverb attachment, and coordination by native and non-native speakers of 
English. The participants parsing preferences was determined through eye-tracking devices. The findings indicated the role of syntax in sentence processing by L2 speakers. In the same line, a number of studies highlighted the role of L2 learner' proficiency level in processing (e.g. Hopp, 2006; Jackson \& Dussias, 2009).

While majority of studies have utilized tasks requiring reading sentences (i.e. comprehension tasks) to investigate ambiguity resolution, Rah and Adone (2010) used a production task in the form of sentence completion. They used sentences with DP1+VP+DP2 structure in two version with either a ditransitive verb (3a) or a transitive verb (3b). The participant were required to complete the sentences with a PP.

(3a) The salesman offered the apples...

(3b) The salesman ate the apples...

The results showed that both L2 learners at two proficiency levels and the native speakers had a VP attachment preference regardless of whether the verb was transitive or interansitive.

The present study is a continuation of Maghsoud's (2018) study on the impact of semantic relationships between intersentential elements using online and offline comprehension tasks. This study investigates L2 learners' PP attachment preferences using a production task.

The rationale behind utilizing a production task was to examine L2 learners' preferences when they are given free choice in absence of prewritten options. For instance, writing the noun phrases GPS, Google, Flashlight, etc. on the dotted line in (4) would represent a participant's preference to integrate the semantic features of search in their processing. On the other hand, completing the sentence by a word such as a black jacket, a nice car or mustache, which does not have a semantic relationship with search, would be an indication of preference to attach the noun phrase to the object. In other words, the former preference would support the constraint-based theories and the latter would represent a syntactic analysis as assumed by the garden path theory.

(4) Andy searched the man with

Moreover, completing the sentences with words which are semantically related to the verb (i.e. semantic-based processing) would show that L2 learners' preferences across the reading (comprehension) tasks used in Maghsoud (2018) and the production task used in the present study do not differ.

The following research questions are addressed in this study.

1. Do Persian speaking second language learners of English prefer to complete sentences with DPs which are semantically related to the verb?

2. Does proficiency level affect the preference of Persian speaking second language learners of English to complete sentences?

\section{Method}

\subsection{Participants}

The participants of the present study were those of Maghsoud (2018). Thirty-four second language learners of English aged between 12 and 24 participated in this study. They were divided into two high and low proficiency levels based on the results of a placement test.

\subsection{Instrument}

A production task was administered in which the participants were instructed to fill in 45 incomplete sentences (15 experimental and 30 filler items) such as (5) using a noun phrase (See for the experimental items). They were also told that a noun phrase could consist of a single noun, a noun preceded by an article or an article plus an adjective plus a noun. For the purpose of illustration, alongside the instructions an example was given, too.

(5) Jim talked to the man with ................ .

Unlike the experimental items, the fillers had a variety of prepositions. Two examples are provided below:

(6) Jane is in love with the man from

(7) Iva bought a gift for

A pseudo-randomization was also used so that each two experimental items were separated by one to three fillers. 


\subsection{Data Collection Procedure}

The production task was administered to learners in groups. The task required the participants to complete sentence fragments with a DP. The participants read the instructions and the example on the answer sheet. Oral explanation was also given to make sure that the participants were aware of what they were required to do. All the participants finished the task in less than 30 minutes.

Moreover, to determine the proficiency level, an Oxford Placement Test (UCLES, 2001), which included cloze and multiple choice tests addressing an integration of knowledge of grammar, vocabulary and pragmatics, was administered to learners on a different day.

\section{Results}

\subsection{Results for the Placement Test}

The mean score for placement test was $23.14(S D=4.03)$. The proficiency levels of the participants who received a score below (16 participants) and above the mean (19 participants) were considered as low and high respectively. The results of an independent samples t-test revealed that the difference between the two groups was statistically significant $\left(\mathrm{t}_{32}=7.604, \mathrm{p}=.000\right)$.

\subsection{Results for the Production Task}

The participants were required to complete 80 percent (24 out of 30 ) of the filler items correctly so that their data could be used in the analysis. The incomplete items or the items with illegible or meaningless replies were excluded from the data. Table 1. provides descriptive statistics for the production task filler items.

Table 1. Descriptive Statistics for Fillers in the Production Task $(\mathrm{N}=34)$

\begin{tabular}{lllll}
\hline & Minimum & Maximum & Mean & Std. Deviation \\
\hline Fillers & 26 & 30 & 29.67 & .91 \\
\hline
\end{tabular}

As it is presented in the table, all the participants completed more the 80 percent of the filler items correctly with the mean of 29.67 ( 98.6 percent).

The categorical data obtained from the experimental items were transformed to percentages to get interval scores. Shapiro-Wilk test was used to check normality. The descriptive statistics for the means of the semantically verb related and unrelated DPs produced by the participants across two proficiency levels are provided in Table 2 .

Table 2. Descriptive Statistics for Semantically Verb Related and Unrelated DP Production across Two Proficiency Levels in the Production Task ( $\mathrm{N}=34)$

\begin{tabular}{ccccc}
\hline & \multicolumn{2}{c}{ Semantically Verb Related DP } & \multicolumn{2}{c}{ Semantically Verb Unrelated DP } \\
\hline Proficiency & Mean & Std. Deviation & Mean & Std. Deviation \\
Low & 75.78 & 15.90 & 12.28 & 12.22 \\
High & 78.22 & 13.67 & 12.88 & 10.22 \\
\hline
\end{tabular}

The table shows that the majority of the sentences were completed with DPs that were semantically related to the verb by both low and high proficiency level participants with the means of 75.78 and 78.22 respectively. Figure 1 . depicts the preferences to produce semantically verb related and unrelated DPs across low and high proficiency levels. 


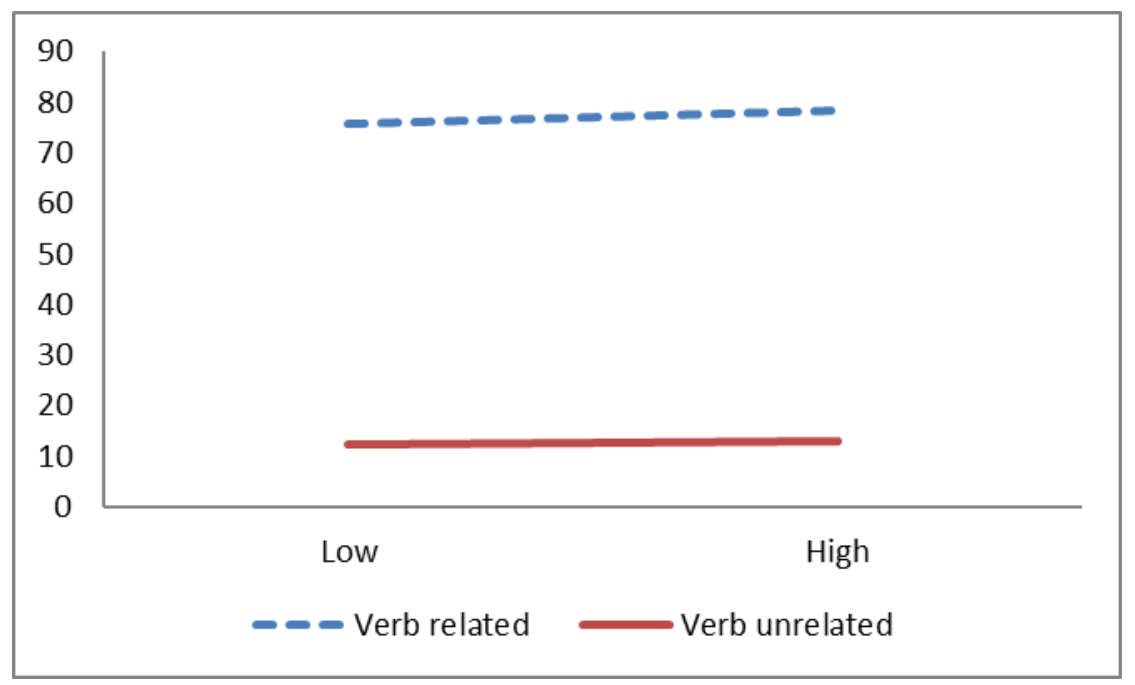

Figure 1. Production of Semantically Verb Related and Unrelated DPs across Different Proficiency Levels in the Production Task

To make certain that the means provided in the table are significantly different, a $2 \times 2$ repeated measures ANOVA was conducted. The within-subjects variable, named condition, was whether the sentences were completed with semantically related or unrelated DPs to the verb. The between-subjects variable was high and low proficiency levels.

Condition had a statistically significant effect on the subjects' attachment preference, $\mathrm{F}(1,32)=217.262, \mathrm{P}=.000$, $\mu^{2}=.872$ However, neither proficiency, $\mathrm{F}(1,32)=1.151, \mathrm{P}=.291, \mu^{2}=.035$ nor interaction between bias and proficiency, $\mathrm{F}(1,32)=.044, \mathrm{P}=.836, \mu^{2}=.001$ had any effect. The effect sizes indicate that condition caused about 87 percent of variation in replies.

\section{Discussion}

The majority of DPs that the participants of both proficiency levels used to complete the sentences had a semantic relationship with the verb. This shows that the semantic features of the verb were taken into account by the participants. Moreover, neither proficiency nor the interaction of proficiency and preference had an influence on attachment preferences. In brief, the findings of the production task suggest that when the individuals are given free choice, they opt for inserting a semantically verb related DP. It seems that, between the two attachment options (i.e. attachment to the verb and to the object DP) L2 learners subconsciously choose the one with semantic support. They might not have even noticed that the sentence could be completed in a different way since the semantic support of the verb for one of the interpretations is very strong.

At first sight, it might seem that the participants had a structure-based or VP attachment preference in their production since they inserted DPs which matched the verb. Nevertheless, it must not be overlooked that the participants' production was on the basis of the semantic features of the verb and not the verb as a grammatical entitiy. This claim is further supported by the fact that even the semantically verb unrelated DPs produced by learners had a semantic relationship with the object DP. Therefore, the factor affecting learners' choices to complete the sentences appears to be intersentential semantic relationships.

Moreover, the participants' preference was not significantly influenced by their proficiency level. In this regard, the findings support shallow structure hypothesis (SSH) (Clahsen \& Felser, 2006), which assumes that L2 learners at different proficiency levels employ other sources of information such as semantics to compensate for their lack of knowledge of grammar. 


\section{Conclusion}

The findings of the present study indicate that the semantic features of the verb play an important role in L2 learners' production since the learners strongly favored to complete the sentences with DPs that were semantically related to the verb. Moreover, the results showed that neither proficiency level nor interaction between proficiency and condition influenced the participants' choice of interpretation in sentence completion. The meaning-based processing shown by L2 learners at different proficiency levels can be explained in light of the constraint-based theories and $\mathrm{SSH}$. Further research is needed to determine what other sources of information other than semantic relationship can influence processing for production as well as comprehension.

\section{References}

Altmann, G., \& Steedman, M. (1988). Interaction with context during human sentence processing. Cognition, 30, 191-238. https://doi.org/10.1016/0010-0277(88)90020-0

Branigan, H. P., Pickering, M. J., \& McLean, J. F. (2005). Priming prepositional-phrase attachment during comprehension. Journal of Experimental Psychology: Learning, Memory, and Cognition, 31(3), 468-481. https://doi.org/10.1037/0278-7393.31.3.468

Britt, M. A., Perfetti, C. A., Garrod, S., \& Rayner, K. (1992). Parsing in discourse: context effects and their limits. Journal of Memory and Language, 31, 293-314. https://doi.org/10.1016/0749-596X(92)90015-P

Clahsen, H., \& Felser, C. (2006). How native-like is non-native language processing? TRENDS in Cognitive Sciences, 10(12), 564-570. https://doi.org/10.1016/j.tics.2006.10.002

Felser, C., Roberts, L., Marinis, T., \& Gross, R. (2003). The processing of ambiguous sentences by first and second language learners of English. Applied Psycholinguistics, 24, 453-489. https://doi.org/10.1017/S0142716403000237

Ferreira, F., \& Clifton, C. (1986). The independence of syntactic processing. Journal of Memory and Language, 25, 348-368. https://doi.org/10.1016/0749-596X(86)90006-9

Frenck-Mestre, C., \& Pynte, J. (1997). Syntactic ambiguity resolution while reading in second and native languages. Quarterly Journal of Experimental Psychology, 50A, 119-148. https://doi.org/10.1080/027249897392251

Hopp, H. (2006). Syntactic features and reanalysis in near-native processing. Second Language Research, 22(3), 369-397. https://doi.org/10.1191/0267658306sr272oa

Jackson, C. N. \& Dussias, P. E. (2009). Cross-linguistic differences and their impact on L2 sentence processing. Bilingualism: Language and Cognition, 12(1), 65-82. https://doi.org/10.1017/S1366728908003908

Maghsoud, H. (in press). Prepositional Phrase Attachment Global Ambiguity Resolution in Semantically Biased and Neutral Conditions by L2 learners. International Journal of English Language Teaching.

McDonald, J. (2006). Beyond the critical period: Processing-based explanations for poor grammaticality judgement performance by late second language learners. Journal of Memory and Language, 55, 381-401. https://doi.org/10.1016/j.jml.2006.06.006

Papadopoulou, D. (2006). Cross-linguistic variation in sentence processing: Evidence from RC attachment from Greek. Dordrecht: Springer. https://doi.org/10.1007/1-4020-4690-1

Papadopoulou, D., \& Clahsen, H. (2003). Parsing strategies in L1 and L2 sentence processing: A study of relative clause attachment in Greek. Studies in Second Language Acquisition, 25, 501-528. https://doi.org/10.1017/S0272263103000214

Rah, A., \& Adone, D. (2010). L2 learners' processing of PP attachment ambiguities: A production study. In Selected Proceedings of the 2008 Second Language Research Forum, (ed.), Matthew T. Prior et al., 139-149.

Tanenhaus, M. K., Spivey-Knowlton, M. J., Eberhard, K. M., \& Sedivy, J. C. (1995). Integration of visual and linguistic information in spoken language comprehension. Science, 268(5217), 1632-1634. https://doi.org/10.1126/science. 7777863

Trueswell, J. C., Tanenhaus, M. K., \& Garnsey, S. M. (1994). Semantic influences on parsing: Use of thematic role information in syntactic ambiguity resolution. Journal of Memory and Language, 33(3), 285-318. https://doi.org/10.1006/jmla.1994.1014 
Witzel, J., Witzel, N., \& Nicol, J. (2012). Deeper than shallow: Evidence for structure-based parsing biases in second-language sentence processing. Applied Psycholinguistics, 33, 419-456. https://doi.org/10.1017/S0142716411000427

\section{Appendix}

Experimental Sentences for the Production Task

1. Alvin hit the man with

2. Martin punished the man with

3. Jim talked to the man with

4. Brian chased the man with

5. Michel attacked the man with

6. John threatened the man with

7. Peter killed the man with

8. Mike saw the man with

9. Sara called the man with

10. Andy shot the man with

11. Ben motivated the man with

12. Carl impressed the man with

13. Brad touched the man with

14. Andy searched the man with

15. Sam frightened the man with 